\title{
Direct Steam Generation for Process Heat using Fresnel Collectors
}

\author{
Marwan Mokhtar ${ }^{\text {a,b }}$, Michael Berger ${ }^{\mathrm{a}}$, Christian Zahler ${ }^{\mathrm{a}}$, Dirk Krüger ${ }^{\mathrm{c}}$, \\ Heiko Schenk ${ }^{d}$, Robert Stieglitz ${ }^{\text {b }}$ \\ ${ }^{a}$ Industrial Solar GmbH, Freiburg, Germany, 79110 \\ ${ }^{b}$ Karlsruhe Institute of Technology, Karlsruhe, Germany, 76131 \\ ${ }^{c}$ German Aerospace Center (DLR), Köln, Germany, 51147 \\ ${ }^{d}$ German Aerospace Center (DLR), Stuttgart, Germany, 70569
}

\begin{abstract}
Industrial energy consumption represents one third of the total energy used worldwide, significant amount of which is thermal energy. This paper discusses the use of Fresnel collectors to provide saturated steam for process heat usage through Direct Steam Generation (DSG) which is a promising technology for introducing solar energy for industrial use. In this work the challenges imposed by the non-linear dynamics of DSG technology in solar system are discussed in addition to the strategies used to overcome these challenges. Moreover, advanced concepts for integrating solar DSG systems in industrial settings are presented in the framework of the SolSteam Project. In addition we present details from the current commercial DSG project being constructed Jordan which represents the first solar DSG plant in MENA.
\end{abstract}

Keywords: Direct Steam Generation, Solar thermal, Fresnel collector, Process heat, Industrial application, SolSteam

\section{Introduction}

Substantial penetration of renewables into the energy system is realistically achieved gradually. Meanwhile, wider acceptance of solar energy as a reliable source of energy can be promoted by mitigating the intermittent nature of solar resource and other disturbances that reduces availability. That is why storage technologies and hybrid fossil-renewable systems represent key technologies in the transition towards an energy sustainable future. Process heat for industrial use represents a considerable consumer of energy worldwide, almost $30 \%$ of total energy demand worldwide is used up by thermal industrial processes. A substantial amount of which is used to generate saturated steam. Solar Direct Steam Generation (DSG) is made possible by solar concentrating technology, and allows for integration with existing fossil based systems. Compared to indirect steam generation, DSG introduces the opportunity of capital cost savings in addition to enhanced performance and lower heat losses. The environmental aspects of not having to use thermal oil in the process is another big advantage of DSG. DSG however presents its own challenges regarding the controllability and stability of the system due to the two phase flows in the absorber tube in addition to the dynamics of the steam drum.

The main objective of the controls of a solar thermal system is to maintain operating conditions within limits against disturbances such as solar irradiation (e.g. caused by clouds), fluid inlet conditions, reflectivity degradation (e.g. caused by soiling) and load variation. This results in a complex control problem which can be described as nonlinear, time variant with pure time delays. Compared to a standard fossil-fuelled heat source which can be easily managed by controlling the fuel supply and eventually reaching steady state conditions, a solar plant may never reach steady state, simply because of the ever changing sun position, solar irradiation and other disturbances. Control stability is essential in the control of a solar thermal plant. If not taken into account, abrupt disturbances (e.g. from clouds) can cause undesirable/dangerous conditions where the plant would have to be shutdown wasting precious energy. This can also call for extra components like thermal inertia and buffer storages to meet the requirements of the process and therefore increasing investment costs.

* Corresponding author. Tel.: +49 761767 111-0, Fax: +49 761 111-99

E-mail: Marwan.mokhtar@industrial-solar.de

(C) 2015 International Association for Sharing Knowledge and Sustainability

DOI: $10.5383 /$ ijtee.10.01.001 
A stable control system can help minimize downtimes and enhance plant availability. This is especially relevant in an industrial settings where a stable, highly available source of heat at specific set-points is not only standard requirement but also taken for granted.

In this paper, the Solar DSG system is described including its hybridization with a fossil boiler. Moreover the most pressing control issues for direct steam generation in Fresnel process heat collectors are discussed with strategies employed to overcome them. Finally other advanced hybrid solar-fossil DSG configurations are described which are developed to simplify and standardize the integration in industrial settings.

\section{Solar Direct Steam Generation System}

Most commercial solar power plants are operated with synthetic oil as the heat transfer fluid (HTF) in the solar field. The solar field is connected via a heat exchanger to the steam turbine circuit. This configuration is simple from controls point of view and does not involve twophase flow complications as in Direct Steam Generation (DSG). However the advantages that DSG offers often outweigh these problems and hence there has been a lot of investigation into resolving the issues associated with DSG operation. DSG advantages can be summarized in the following main points according to [1]

- Avoiding environmental risks associated with synthetic oil usage

- No limit on steam temperature

- Simpler overall plant configuration

- Lower investment and operation and maintenance costs

Three main DSG concepts were investigated by workers in the field, namely: Once-Through, Recirculation and Injection concepts, as depicted in Figure 1.

In the once through concept, water is fed into the solar field from one end and exits as superheated steam at the other end in one pass only, hence the name. This concept is the least complex from hydraulic design view point and requires the least investment cost. The dangers associated with thermo-mechanical stresses in the superheater section and the controllability of the system, are the main hurdles of this concept [1-4]

In the Injection concept, water is injected at several points along the absorber tube to control the evaporation process. The complexity and cost of this concept are the main challenges. [1-4]

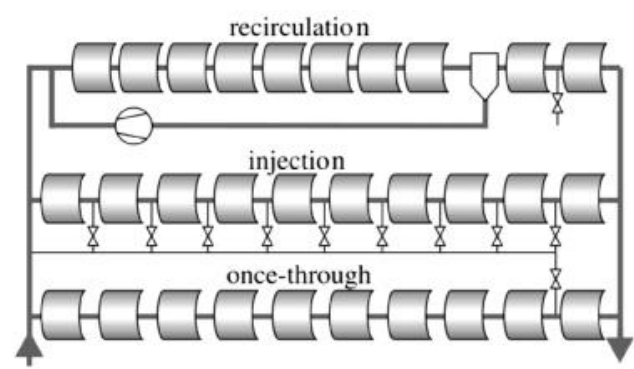

Figure 1 Solar-DSG concepts for Parabolic Trough Plants [5].

The direct steam generation system adopted by Industrial Solar is the recirculation mode. In recirculation mode, more liquid than can be evaporated is circulated in the solar field. The ratio is around $50 \%$ to $80 \%$. This means that more pumping power is needed, an extra pump and a separator compared to the once through concept for example.

The advantage of the recirculation concept is the reliability and safety aspects. The main function of this extra liquid which is circulated around is to prevent the absorbers from overheating.

The recirculation concept is the most controllable system among the three concepts; however it still suffers from the two phase flow problems in the absorbers and from the instability issues during transience. These problems are addressed through advanced control techniques.

\section{Process heat DSG Plant in Jordan}

The first DSG plant for process heat in MENA is currently being constructed in Amman, Jordan (

Figure 2). The commissioning is due in mid-2015. This plant is going to supply RAM Pharmaceutical Company with saturated steam necessary for their industrial process.

The solar field consists of 18 modules of Industrial Solar's Linear Fresnel collector (Figure 3) arranged in two parallel strings of $36.5 \mathrm{~m}$ each. The primary reflective area of the solar field is $396 \mathrm{~m}^{2}$.

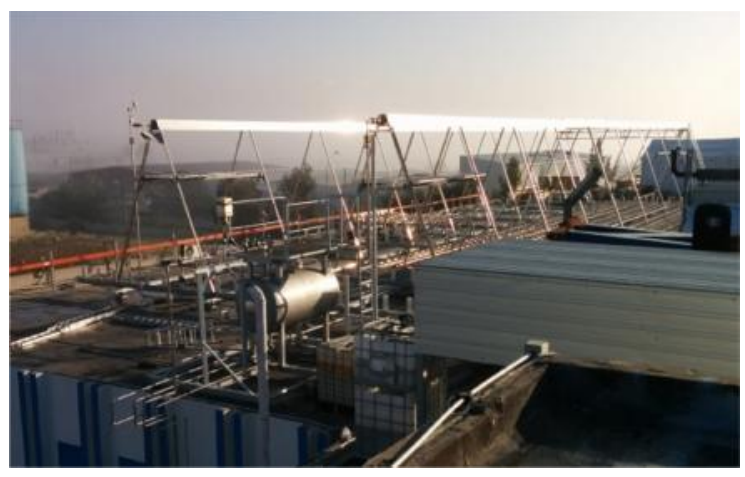

Figure 2 The solar-DSG plant under construction in Jordan Photo from December 2014 
The plant will operate in sliding pressure mode reaching a maximum operating pressure of $15.5 \mathrm{bar}_{\mathrm{g}}$ and temperature of $200^{\circ} \mathrm{C}$. The peak power of the plant is $222 \mathrm{~kW}$ and the gross heat production of the solar plant is $340 \mathrm{MWh} / \mathrm{a}$.

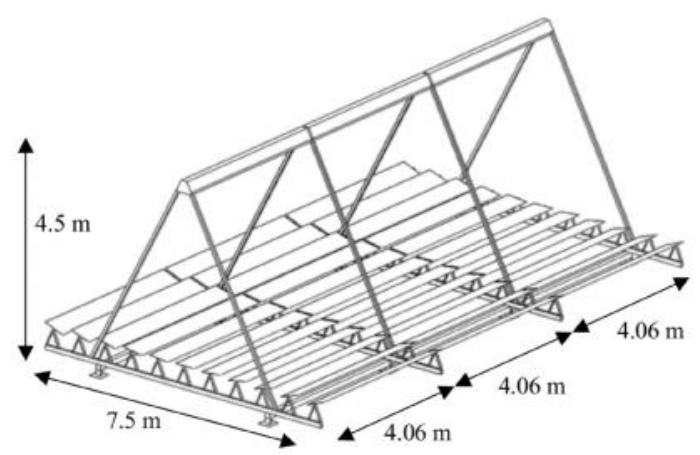

Figure 3 Schematic diagram of Industrial Solar's Linear Fresnel Collector LF-11

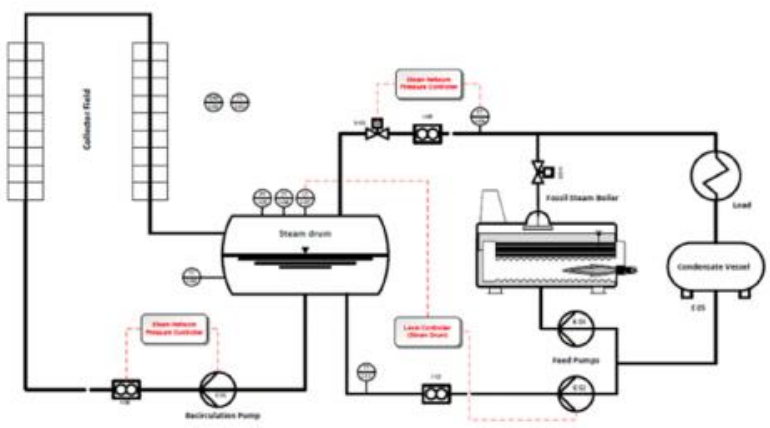

Figure 4 Schematic of the solar- DSG plant in Jordan. The system operates parallel to a fossil fired steam boiler to provide process steam.

As can be seen in the schematic in Figure 4, the plant is configured in recirculation mode where the two-phase flow from the solar field is fed into the steam drum. The separated saturated steam is then fed into the steam network in a controlled manner through the steam exit valve. The supply pressure of the solar system is controlled to ensure that the solar system has priority over the fossil boiler. This is achieved by supplying steam at a pressure higher than the boiler setpoint but not largely above the steam demand setpoint.

As mentioned earlier, the output of the solar field is connected to a $2.0 \mathrm{~m}^{3}$ stainless steel pressure vessel, the steam drum. The steam drum performs several essential functions in the system, which are described below:

(a) Phase Separation: The recirculation concept requires a separator for removing saturated steam from the two phase mix. To perform this task, the steam drum is partially filled with liquid water and the upper void is occupied by saturated steam. As the two phase flow, enters the steam drum from the side, the steam will stay on top while water drops to the liquid pool. This is further enhanced by metal sheets that reduce the momentum of water droplets carried by the steam forcing them to settle in the liquid pool.

(b) Pressure Maintenance: Any fixed volume hydraulic system which encounters temperature variations needs a means to compensate for volume changes with temperature. Compressed liquid systems would require a dedicated system for compensating volume changes which are in the form of a diaphragm vessels or pressure controlled pump stations. In this DSG system, the compressibility of the steam in the upper part of the steam drum is exploited to provide some compensation for the changes in the liquid volume. Hence a dedicated pressure maintenance system is avoided.

(c) Buffer Storage: Renewable energy systems suffer from uncontrollable resource transience and solar energy is no exception. The steam drum helps in mitigating this problem by providing a buffer against these transients. Energy is mainly stored in the liquid and in the metallic parts of the steam drum. This energy is stored as sensible heat at a pressure higher than the steam network setpoint. The steam drum is considered fully charged when the pressure of the steam drum reaches its maximum at $16.0 \mathrm{bar}_{\mathrm{g}}$. And completely drained when the pressure reaches $8.0 \mathrm{bar}_{\mathrm{g}}$. This is the network setpoiont. Notice that reducing the network setpoint or increasing the maximum pressure will increase the storage capacity. The size of the steam drum installed in this system is enough to provide 16 to 22 minutes of buffer storage at full load, assuming the network pressure being between $8.0 \mathrm{bar}_{\mathrm{g}}$ and $6.0 \mathrm{bar}_{\mathrm{g}}$ respectively. Notice that $8.2 \%$ of the energy is actually stored in the metal of the steam drum.

(d) Water Reservoir: An often overlooked problem is the fact that the solar system has to be shut down and started every day. In the absence of the heating source, all the two phase flow sections will be filled with liquid water. This extra water, which is needed to fill the void left by the condensing steam in those sections, is provided by the steam drum. This can be a significant amount of water accounting for around $10 \%$ of steam drum total volume. Typically, the steam drum is the only place where the two phases exist after a shutdown.

At the top of the steam drum, the steam valve is located which provides an exit to the steam separated from the two phase flow. The steam valve also controls the flow 
of the steam to the load steam network. The target is to maintain the pressure in the load network as long as solar steam is available. If the solar steam is available but there is no demand, then the steam valve will close and allow the charging of the steam drum. The valve also has the possibility to do a fast shutdown $(8.0 \mathrm{sec})$ to prevent over pressurization in the steam network. If the storage is fully charged then the system will defocus the mirrors to prevent overpressure in the solar system. In case not enough solar steam is available, the steam exit valve will deplete the storage by providing flash steam up until the pressure of the steam drum is close to the steam network pressure.

\section{Control of Solar Direct Steam Generation Systems}

As discussed before, the solar system is configured in recirculation mode, where the two phase flow of the collector field is fed into the steam drum. In the steam drum the phases are separated. The solar steam is then taken from the top of the steam drum through a regulating valve that controls the pressure in the steam network. If the solar steam is not able to satisfy the demand, the fossil boiler is used to cover the shortage. This is indirectly achieved when the pressure falls below the boiler setpoint.

Within the solar system, the control task is more complicated. Indeed, one of the greatest technical challenges related to DSG is that of control. System control during transience and abrupt changes in operating conditions is a significant challenge. The solar DSG system is a Multi Input Multi Output (MIMO) system which needs several controllers to maintain its steady operation. Given the co-dependency of the controlled variables and the time variant non-linear dynamics, advanced control techniques are required. Three main controllers are used to maintain the DSG system in operation (see Figure 4):

(a) Recirculation flow controller: This controller has the task of maintaining enough flow in the absorbers to prevent overheating. This is especially important during transient conditions when the flow rate changes as a result of pressure drop variation across the absorber. The change in pressure drop is induced by two phase flow dynamics and can lead to flow instabilities (e.g. see Ledinegg instability). Through this flow rate, the steam quality at the solar field outlet is also determined.

(b) Feedwater Controller: This controller will control the supply of feedwater to the system. The main task of this controller is to prevent the level of the steam drum from exceeding the limits. Although from storage capacity point if view, the steam drum liquid level should be as high as possible, it should not be too high to cause water carry over with steam exit and not too low to starve the recirculation pump. Although this might seem straight forward enough, the changes of the water content of the collector field combined with changes of liquid volume and the presence of steam bubbles under the liquid level prove to be hard challenges to resolve and result in a non-minimum phase control problem as detailed in [6].

(c) Steam Network Pressure Controller: The pressure controller maintains the pressure of the steam network at the required set point. The controller can be linear in the regulation pressure range however at the event where there is no enough steam in the steam drum, the pressure controller should close the regulating valve. Moreover, in the case when the demand in the steam network is cut-off the control valve should also close rapidly to prevent over pressurizing the steam network. This behavior cannot be handled by a pure linear controller.

During stable conditions of solar irradiation and steam demand (steady state), the level of the liquid is maintained by matching the amount of steam drawn from the steam drum and the feed water flow. Moreover, the energy extracted from the steam drum through the out flowing steam should match the net energy provided to the system through solar energy and feedwater. If these conditions are met, an energy and mass balance will be achieved resulting in stable operating conditions of pressure and steam drum level.

This however is rarely the case. Solar irradiation will change continuously and so will the demand, which will result in departure from steady state conditions.

In certain case, if the changes are slow enough, the solar system will behave in a stable manner and simple linear controllers will handle the job quite well. For example if the load is increased slowly, the load controller will increase the steam valve opening gradually resulting in an increase in the steam mass flow at the drum outlet. This will eventually result in gradual decrease of steam drum liquid level. Consequently the steam drum level controller will increase the flow of feedwater to compensate. In this scenario the controllers behave as they should and simple PID controls will be able to do the job.

Problems arise when the changes are not as smooth or slow, or if solar irradiation does not match the demand. For example, when the DNI drops suddenly because of a cloud. If the load is maintained, the pressure in the steam drum will fall because the load continued without any energy supply. The steam flow will start dropping as the pressure drops, this should logically result in reduction of the feed water flow rate. This does not happen however as depicted in Figure 5. This is because, when a drop in DNI occurs, liquid from the steam drum is used to fill up the absorber tube which results in quick drop in the steam drum level and hence an increase in the feedwater flow, which is the opposite to what should be done. This further complicates the problem since the cold feedwater results in further drop in pressure. 
To avoid such problems where classic controllers fail to satisfy the requirements. Several rules have to be set to each specific system dynamic that can cause a problem. This requires deep knowledge of the system dynamics that can cause problems including procedures to detect them and methods to deal with them. This can be achieved by a combination of setpoint scheduling, feedforward and anti-windup techniques. Although classic methods can provide a stable and acceptable performance. The hassle remains in dealing with several controllers and having to tune them and to deal with those unconventional dynamic states when the controllers should be switched or adapted. Not to mention the dynamics which are not accounted. To that end, model based control techniques, like Model
Predictive Control or (MPC) present an attractive solution since it combines all these controllers and constraints in one universal control law. The obvious disadvantage is that MPC needs a model to operate. The degree of complexity of the model depends on the dynamics we are interested in, the bottom line is that if you need the controller to deal with a certain dynamic issue, then the model has to be able to predict it. The second challenge with MPC is that it requires the solution of an optimization problem at each time step. Which means that the model has to be really simple enough that the optimization is solved in closed form, for example in a linear system with no conctraints, or a considerable computational power should be available to solve the optimization problem. (Figure 6) .

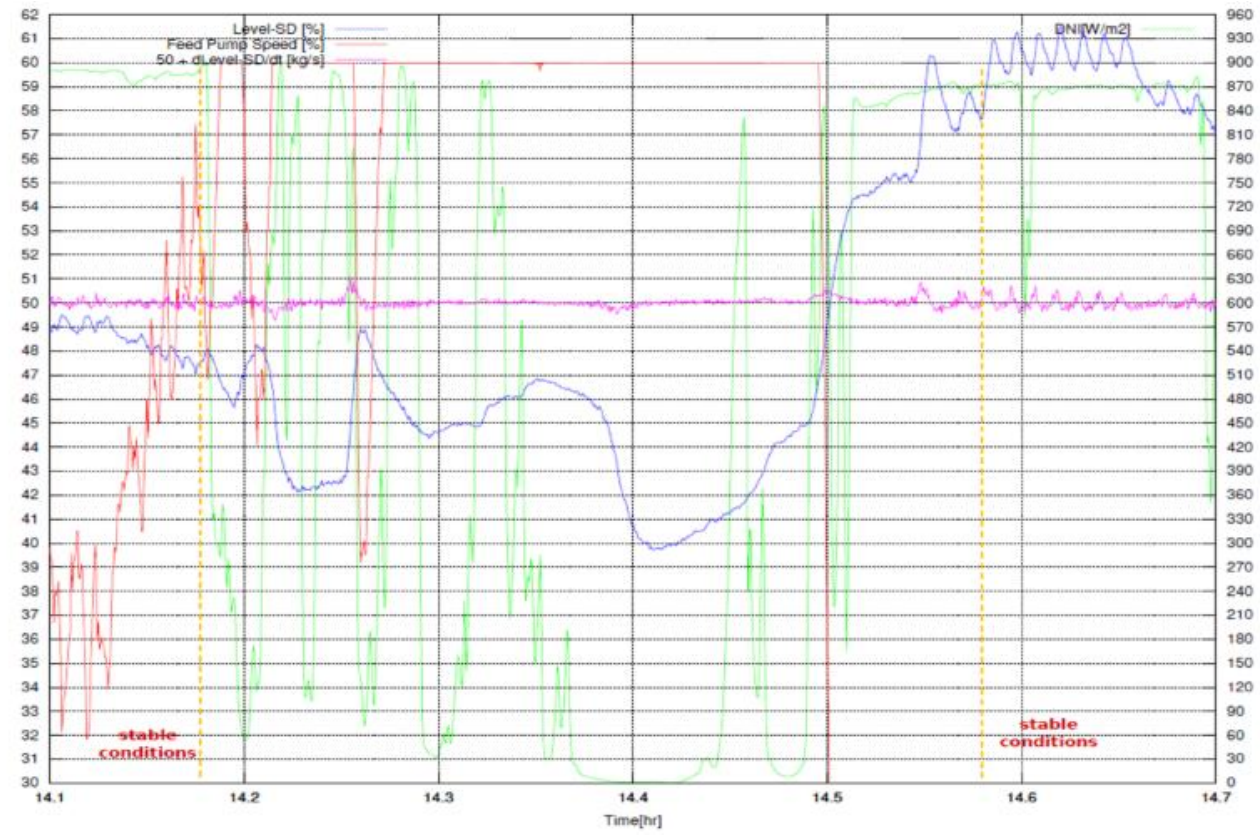

Figure 5 An example of non-linear dynamics of the DSG system. Effect of sudden DNI drop on steam drum level.

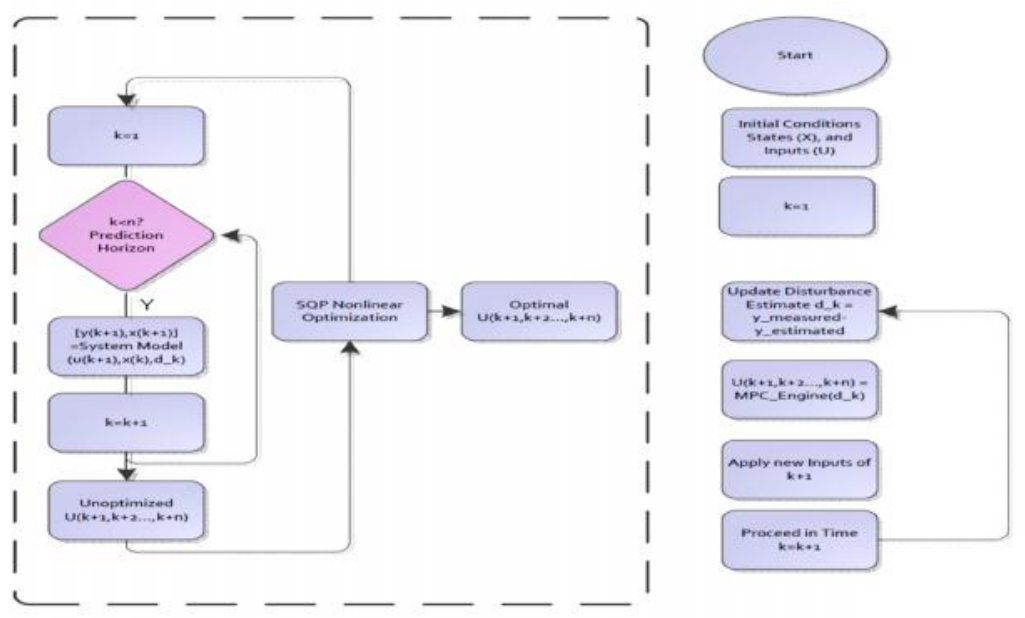

Figure 6 Model Predictive Control Flow Chart 


\section{SolSteam - Development of DSG Configurations for a standard hybrid system}

Viessmann, a leading provider of industrial steam boilers, and Industrial Solar have joined forces to develop a standardized solar-fossil fuel powered steam generation system for industrial applications. The two industrial partners are being supported by the German Aerospace Center, DLR, which has more than 20 years of research experience with concentrating solar thermal technologies and direct steam generation. The development is funded by the Federal Environment Ministry under the project title "SolSteam", and forms the basis for the development of a commercially available product. The project SolSteam aims to answer the basic technical questions of combining a direct steam generating solar collector with a fossil fuel fired steam generator, thereby laying the foundation for the development of a solar-fossil fuel hybrid system. The commercial availability of such a system is the precondition for swift entry of renewable energy into the industrial process heat market. This solution combines cost-efficiency with security of steam supply.

The project officially started in August 2013 and will continue till mid of 2017. After identifying market requirements, a wide screening of different concepts for a standard hybrid system has been made and the three most promising integration concepts have been chosen. One of these concepts is the plant being installed in Jordan. Within SolSteam project, the installation in Jordan shall be monitored as a pilot system for further optimization and eventually be used as a basis for a standard package hybrid system.

\subsection{Integration concepts}

As mentioned above, after a screening of various integration concepts, three basic concepts (A, B and C) turned out to be most promising.

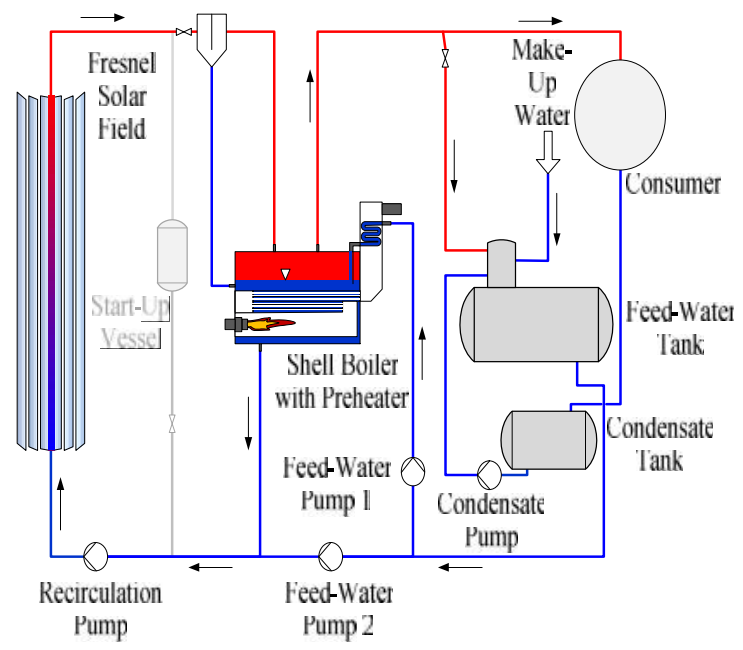

Figure 7 SolSteam DSG Concept A.
Within two of the concepts (A, B), liquid water enters the solar field and is heated up to the boiling point. To avoid overheating and mechanical stress on the absorbers the control system must ensure that a portion of liquid water remains in the flow to cool the absorbers, resulting in a water-steam mixture leaving the solar field. This design requires a steam drum or a separator for the separation of steam from liquid water. In Concept A (Figure 7), the separated flows are then led into the steam boiler, which compensates for fluctuations and provides the desired steam flow to the customer. In concept B (Figure 4), a steam drum and the steam boiler are connected to the customer's steam grid in parallel. The steam drum in this concept also acts as short-time buffer storage for transient operation conditions.

In the third concept, the solar collector is operated with pressurized water, and heat exchanger coils inside the steam boiler convert the solar heat into produced steam.

The three solar-hybrid integration concepts have been compared qualitatively in a first step, and in a second step in a techno-economic analysis. The results show, the concept A is the preferable solution in terms of thermodynamic performance, while concept $\mathrm{B}$ has higher operational experience and concept $\mathrm{C}$ has the lowest investment costs. The differences of the three concepts in

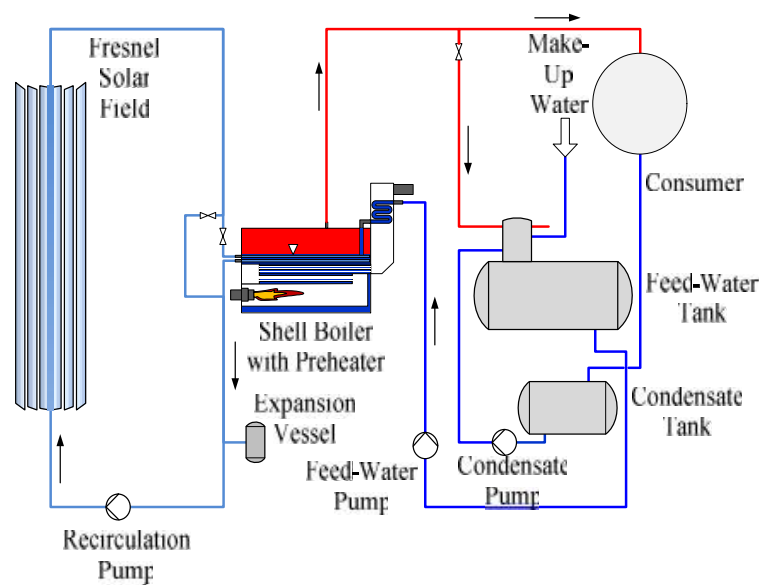

performance and cost showed to be small as a result of a pre-engineering and yearly performance simulation.

Figure 8 SolSteam DSG concept C.

\subsection{Monitoring}

The new installation at RAM resembles integration concept B. Following commissioning of the facility, test measurements will begin. Steady-state operation and robust start-up and shut-down strategies will be tested. With load changes, the dynamic behavior of the collector field and boiler will be examined so that operation and control strategies can be optimized. DLR will carry out an evaluation of the collector field quality. 
The system behavior under various conditions will be tested. This includes extreme temperatures, power failure, and failure of individual components, such as the tracking system or pump. Various interconnections, such as once-through in comparison with a partial recirculation will be tested. From these tests and from the influence of the user's behavior, optimized operation will be determined, as well as the extent of fuel savings.

\section{Acknowledgments}

The project SolSteam is funded by the German Federal Ministry for Economic Affairs and Energy (BMWi).

\section{References}

[1] E. Zarza; L.Gonzalez; A. Morales; E. Rojas; K. Hennecke; M.Eck;O.Goebel; P. Geskes; S. Zunft; F. Lippke; U. Hermann; J. Langenkamp. Diss-phase i project. Technical Report JOR3-CT95-0058, CIEMAT, DLR, ZSW, PILKINGTON, 1998.
[2] M Eck, E Zarza, M Eickhoff, J Rheinländer, and L Valenzuela. Applied research concerning the direct steam generation in parabolic troughs. Solar Energy, 74(4):341-351, 2003.

[3] Loreto Valenzuela, Eduardo Zarza, Manuel Berenguel, and Eduardo F Camacho. Control concepts for direct steam generation in parabolic troughs. Solar Energy, 78(2):301-311, 2005.

[4] Eduardo Zarza, Loreto Valenzuela, Javier Leon, Klaus Hennecke, Markus Eck, H Weyers, Martin Eickhoff, et al. Direct steam generation in parabolic troughs: Final results and conclusions of the diss project. Energy, 29(5):635-644, 2004.

[5] Markus Eck and Tobias Hirsch. Dynamics and control of parabolic trough collector loops with direct steam generation. Solar Energy,81(2):268-279, 2007.

[6] Karl Johan _Astrom and Rodney D Bell. Drum-boiler dynamics. Automatica, 36(3):363-378, 2000. 